\title{
Effect of Gamma Radiation on Lipids by the TBARS and NMR
}

\author{
Adriana Cristina de Oliveira Silva ${ }^{1 *}$, Eliane Teixeira Mársico ${ }^{2}$, Edgar Francisco Oliveira \\ de Jesus $^{3}$, Carlos Frederico Guimarães ${ }^{2}$ and Marco Antonio Sloboda Cortez ${ }^{1}$ \\ ${ }^{1}$ Laboratório de Inspeção e Tecnologia de Leite e Derivados Lácteos; Faculdade de Medicina Veterinária; \\ Universidade Federal Fluminense; Niterói - RJ - Brasil. ${ }^{2}$ Laboratório de Controle Físico-Químico de Produtos de \\ Origem Animal; Faculdade de Medicina Veterinária; Universidade Federal Fluminense; C. P.: 64; 24230-340; \\ Niterói - RJ - Brasil. ${ }^{3}$ Laboratório de Instrumentação Nuclear; Instituto Alberto Luiz Coimbra de Pós-graduação e \\ Pesquisa de Engenharia; Universidade Federal do Rio de Janeiro; Rio de Janeiro - RJ - Brasil
}

\begin{abstract}
The aim of this work was to study the effect of gamma radiation on lipids by TBARS and NMR. The samples of raw whole milk were subjected to gamma radiation from $\mathrm{Co}^{60}$ in doses of 1,2 and $3 \mathrm{kGy}$ and the production of rancidity was studied through Nuclear Magnetic Resonance (NMR) and Thiobarbituric Acid Test (2-TBARS). The TBARS values increased according to the intensity of the radiation dose applied at the samples, demonstrating correlation between the radiation dose and the production of lipid oxidation. This was confirmed by NMR with the formation of peaks of aldehydes and ketones that were small and similar in the doses of 1 and $2 k G y$. In the dose of $3 k G y$, the total degradation of milk fat was observed. A correlation between the NMR and 2-TBA was detected.
\end{abstract}

Key words: Milk, gamma radiation, rancidity, Thiobarbituric Acid Test, Nuclear Magnetic Resonance (NMR)

\section{INTRODUCTION}

The food radiation is a physical process of conservation that consists of the exposure of foods to sources of ionizing radiation to satisfy four principal objectives: sterilization, pasteurization, disinfestation and inhibition of germination (Gava, 1999). At present, around 50 countries allow the use of gamma radiation for the treatment of at least one or more foods or classes of foods and more than 30 countries are applying gamma radiation to the goods in the raw state for commercial purposes (Farkas, 2006).

Elevated radiation is able to ionize the molecules of water, leading to the formation of free radicals such as $\mathrm{OH}^{-}$and $\mathrm{O}_{2}$. These free radicals have the advantage of being microbiocides; however, they have been related to lipid oxidation (Donnelly and Robinson, 1995), specially of the unsaturated fats, though the process could be delayed, for example, by irradiating foods packed in a vacuum, or under a modified atmosphere (Kilcast, 1995).

Due to the characteristics of composition, that is, a high quantity of water and the presence of saturated and unsaturated fats, milk and its derivatives are sensitive to oxidative rancidness after radiation treatment, which in many cases makes the products unacceptable for the consumption because of the presence of unwanted flavor. For this reason, studies using radiation on

*Author for correspondence: vetdri@gmail.com 
fluid milk and dairy products have been seldom done, in spite of work having been done in recent decades to examine the efficiency of radiation on the reduction of microorganisms which contaminate and deteriorate fluid milk (Naghmoush et al., 1983; Rosenthal et al., 1983; Schoonmaker, 2001; Searle and Mcathey, 1989), on the chemical-physical and sensory characteristics of irradiated milk (Ciesla, et al., 2004; Guimarães et al., 2005) and on its effects on milk derivatives (Gurgel, 2000; Hashisaka et al., 1990; Pietranera et al., 2003; Silva, 2003).

There are at present several methods for detection of rancidity in foodstuffs. The acid 2Thiobarbituric (2-TBA) is the method of choice for detecting the oxidation of lipids in biological systems, when speed and cost reduction is desired, besides being reproducible and being correlated with sensory analyses. Another technique that has good results regarding the alterations of milk components is Nuclear Magnetic Resonance Spectroscopy (NMR) (Andreotti et al., 2000), since it is not an invasive methodology, preserving the structure of the foods, enabling the extraction of useful information from very complex and highly heterogeneous systems (Hu et al., 2004).

Therefore, the objective of this study was to evaluate the formation of secondary products of lipid oxidation in raw milk by the methods of TBARS and NMR and to establish a correlation between the results obtained by both methods.

\section{MATERIAL AND METHODS}

\section{Obtaining the Samples}

The samples of raw whole milk used were donated by the "Indústria de Laticínios Companhia do Leite - Maraporã" an Industrial Farming Cooperativa Ltda, SIE/RJ $n^{\circ} 638$ located in the municipality of Cachoeiras de Macacu (Macacu Waterfalls) - Rio de Janeiro, Brazil. The samples were subdivided into four experimental groups: Control (sample not radiated), samples radiated in the doses of 1, 2 and $3 \mathrm{kGy}$. For each group, six repetitions were carried out, thus completing 24 samples of raw whole milk, each one of them containing $200 \mathrm{~mL}$.

\section{Radiation of the Sample Milk Units}

The samples were transported refrigerated at 5$7^{\circ} \mathrm{C}$ in plastic containers previously sterilized.
Upon arrival at the laboratory they were irradiated under refrigeration aided by recyclable ice, in the Cobalt 60 irradiator model Gammacell Nordion Canada, in the doses of 1, 2 and $3 \mathrm{kGy}$ (rate 45 Grays/minute) in accordance with the corresponding experimental group. The control sample remained under refrigeration and was not irradiated.

\section{Determination of Rancidity by TBA}

The samples were subjected to analysis with 2Thiobarbituric acid immediately after the arrival at the laboratory, according to the methodology described by Dunkley and Jennings (1951). For this analysis, $10 \mathrm{~mL}$ of milk was taken in a centrifuge tube of approximately $40 \mathrm{~mL}$. Next, 5 $\mathrm{mL}$ of the TBA reagent ${ }^{2}$ was added to the tubes that were then homogenized. The tubes were put to boil for 10 minutes and subsequently cooled in cold water. After cooling, $15 \mathrm{~mL}$ of the extraction reagent was added to the tube ${ }^{3}$ and mixed homogeneously for 30 seconds. To get limpid extract, the tubes were centrifuged for 5 minutes at $3,600 \mathrm{rpm}$. The reading was conducted out at $535 \mathrm{~nm}$ in a spectrophotometer (brand SHIMADZU, Model UV 160A). The procedure was repeated six times.

\section{Determination of Secondary Products of Lipid Oxidation by NMR \\ Extraction of the lipids}

After the arrival at the laboratory, the samples of raw cooled milk (irradiated and control) were subjected to centrifugation for 45 minutes at 3,600 RPM in a centrifuge (brand SIGMA, model 6-15) to facilitate the separation of the fat from the milk (Hu et al., 2004). This operation was repeated three times. The supernatant (fat) was frozen at $20^{\circ} \mathrm{C}$ for the analysis.

\section{NMR}

The fat of the milk was analyzed in the Nuclear Magnetic Resonance in the Varian Unity-300 spectrometer at the frequency of $75.429 \mathrm{MHz}$ for carbon 13. The material analyzed was dissolved in deuterated chloroform $\left(\mathrm{CDCl}_{3}\right)$ of the SIGMA brand and was then put into special NMR tubes $(5 \mathrm{~mm})$. All the experiments were done at room temperature $\left(25^{\circ} \mathrm{C}\right)$. The spectral window used in the analysis was $230 \mathrm{ppm}$, taking into account that

\footnotetext{
${ }^{2}$ TBA: $0.025 \mathrm{M}$ of TBA in phosphoric acid. Preparation: equal volume of $0.05 \mathrm{M}$ TBA to $2 \mathrm{M}$ of phosphoric acid.

${ }^{3} 2: 1$ of isoamilic acid and pyridine.
} 
the peaks of interest for the observation, related to ketone and aldehyde, were above 200 ppm.

\section{Statistical analysis}

In the determination of the TBARS value, the data were treated by the analysis of variance (ANOVA) and Dunca's new range test was applied to find out the significant $(\mathrm{P}<0,05)$ differences among the means using the SAS software (1999).

\section{RESULTS}

\section{Substances Reactive to TBARS}

Table 1 shows the average TBARS values of the samples of raw whole milk in the control and when they were irradiated with the doses of 1,2 and $3 \mathrm{kGy}$. The values differed significantly between them at the level of $5 \%$ of probability, demonstrating that the radiation influenced the production of lipid oxidation. The average value determined for substances reactive to TBARS was highest in the samples of milk irradiated with 3 kGy (mean $0.43 \pm 0.12$ ), declining according to the radiation dosage (mean of $0.29 \pm 0.07$ at the dose of $2 \mathrm{kGy}$ and mean $0.19 \pm 0.07$ at the dose of $1 \mathrm{kGy})$. For the control sample, the mean value of $0.11 \pm 0.05$ was obtained.

The formation of the colorimetric complex was more intense according to the increase of the dose of radiation.

Table 1 - Average percentage $( \pm \mathrm{DP})$ of TBARS in samples of cooled raw milk not irradiated and irradiated with doses of 1,2 and $3 \mathrm{kGy}$.

\begin{tabular}{ccccc}
\hline Repetitions & \multicolumn{4}{c}{ SAMPLES } \\
\hline & Control & 1kGy & 2kGy & 3kGy \\
\hline 1 & 0.12 & 0.29 & 0.34 & 0.57 \\
2 & 0.04 & 0.25 & 0.33 & 0.59 \\
3 & 0.01 & 0.11 & 0.38 & 0.41 \\
4 & 0.10 & 0.18 & 0.22 & 0.32 \\
5 & 0.01 & 0.14 & 0.29 & 0.31 \\
6 & 0.01 & 0.14 & 0.21 & 0.37 \\
MEAN & $0.05_{\mathrm{a}}$ & $0.19_{\mathrm{b}}$ & $0.29_{\mathrm{c}}$ & $0.43_{\mathrm{d}}$ \\
DP & 0.05 & 0.07 & 0.07 & 0.12 \\
\hline
\end{tabular}

* Different letters indicate that samples differ between them statistically at the level of 5\%.

\section{NMR}

The data obtained through NMR showed modification at the molecular structure of the lipid of the milk, when subjected to gamma radiation at any experimental dose (Fig.1, 2, 3 and 4). The spectra using the nuclei of Carbon 13 of the samples irradiated showed the presence of aldehydes and ketones, and also the appearance of peaks taking place around 202 and 209 ppm resulting from the $\beta$-oxidation of the fat. These peaks results were not noticed in the control sample. The peaks were highest in the sample irradiated with $3 \mathrm{kGy}$, demonstrating a total degradation of the fat in the absence of the carboxylic acid peak (Fig. 4).

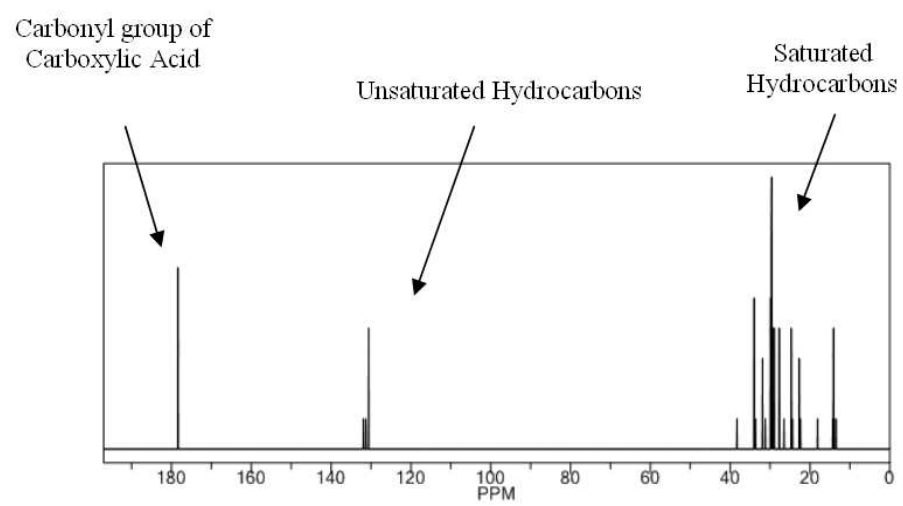

Figure 1 - Graphic representation of the peaks of carboxyl acid (180 ppm), unsaturated fatty acids (130 to $132 \mathrm{ppm})$ and saturated fatty acids (11 to $40 \mathrm{ppm}$ ) of the control sample obtained in NMR using carbon 13. 


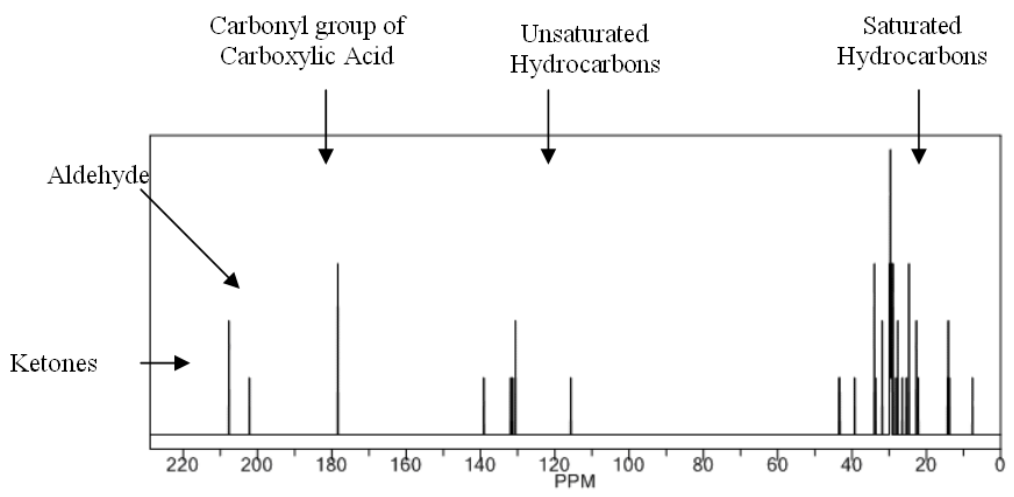

Figure 2 - Graphic representation of the peaks of ketone (209 ppm), aldehyde (202 ppm), carboxylic acid (180 ppm), unsaturated fatty acid (130 to 132ppm) and saturated fatty acids (11 to $40 \mathrm{ppm}$ ) of the sample irradiated at the dose of $1 \mathrm{kGy}$ obtained in the NMR when using carbon13.

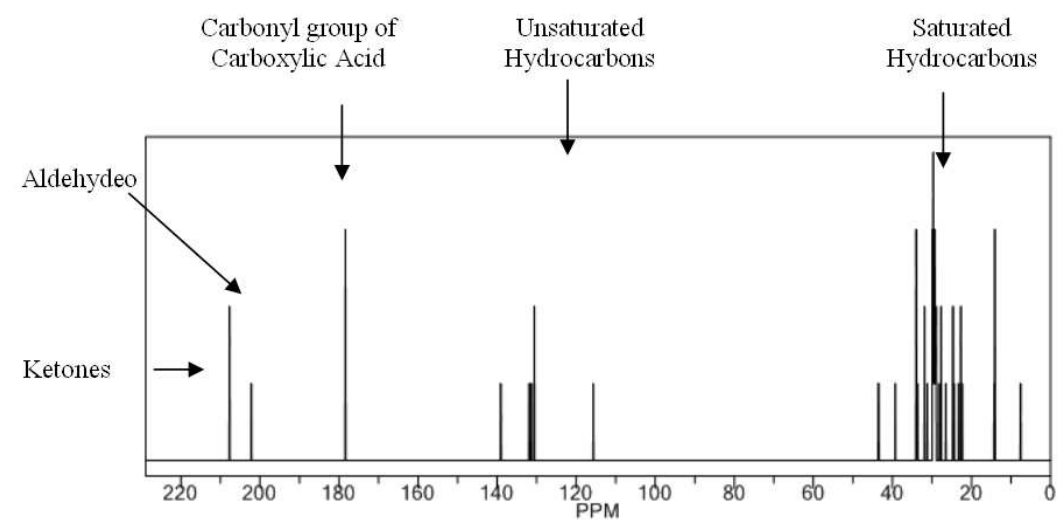

Figure 3 - Graphic representation of the peaks of ketone (209 ppm), aldehyde (202 ppm), carboxylic acid (180 ppm), unsaturated fatty acid (130 to 132ppm) and saturated fatty acids (11 to $40 \mathrm{ppm}$ ) of the sample irradiated at the dose of $2 \mathrm{kGy}$ obtained in the NMR when using carbon13.

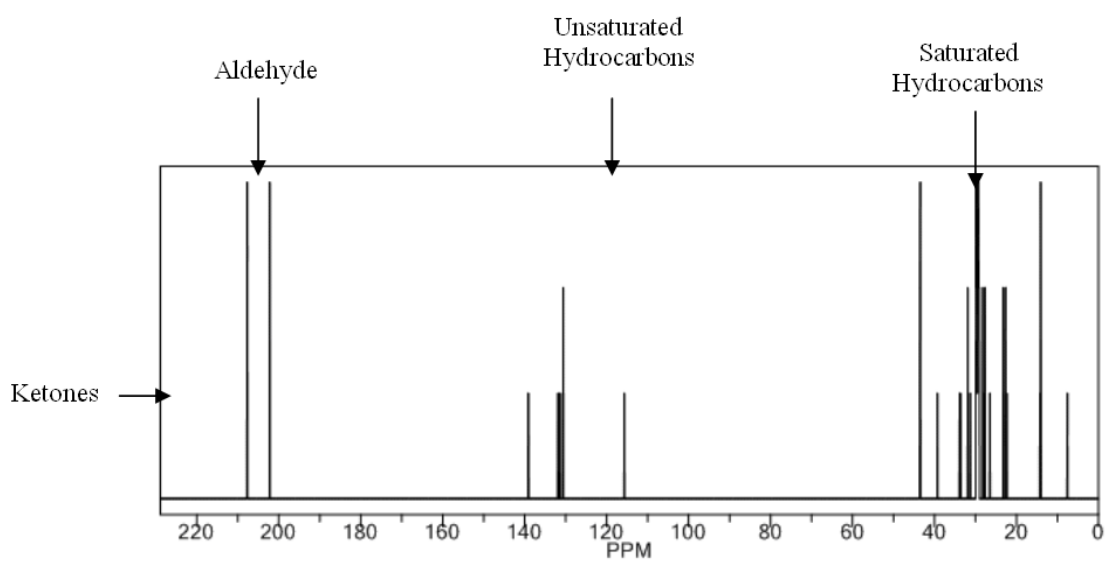

Figure 4 - Graphic representation of the peaks of ketone (209 ppm), aldehyde (202 ppm), unsaturated fatty acid (130 to $132 \mathrm{ppm})$ and saturated fatty acids (11 to $40 \mathrm{ppm})$ of the sample irradiated at the dose of $3 \mathrm{kGy}$ obtained in the NMR when using carbon13. 


\section{DISCUSSION}

The results on the degrading oxidation alterations evaluated by the TBARS and NMR showed that the gamma radiation even in small doses was able to produce alterations in the lipid in raw whole milk, with the liberation of malonaldehyde and other substances reactive to the 2-TBA acid, increasing proportionally the intensity of the coloration produced. This modification was demonstrated to be visually more intense according to the dose applied, indicating good reproducibility (R2>72\%) ${ }^{4}$ and sensitivity, as in the work carried out by King (1962).

The aldehyde and ketone peaks found by NMR, however, demonstrated that the doses of 1 and 2 kGy were very similar, with small alterations in the lipid structure and that in the $3 \mathrm{kGy}$ dose, the alteration was intense, demonstrating total degradation of the lipids with this treatment.

These data did not confirm the results found by Day and Papaioannou (1963) who did not find linearity between the quantity of dose applied and the intensity of color detected by the 2-TBA methodology nor in the quantity of free carbonyls by the technique of Gas Chromatography. This difference could be explained because of high doses of gamma radiation $(15,30$ and $45 \mathrm{kGy})$ used by these authors, which possibly caused very intense alterations in the structure of the lipids. Results found in the present study were similar to that of Guimarães et al. (2005) who found that the alterations in the molecular structure of the milk fat undergoing radiation in the doses from 1 to 2 kGy were small and that in the doses of 3 and 4 $\mathrm{kGy}$ destruction of the lipids took place.

In spite of not being a quantitative methodology, the results found in the NMR managed to characterize in clear form the alterations caused by the gamma radiation in the fat of milk. There are reports on the lipid oxidation caused by irradiation in milk and derivatives by the methodologies of iodine rate (Day and Papaioannou, 1963) peroxide rate (Baky et al., 1986; Ibrahim et al., 1987; Searle and Mcathey, 1989), and quantification of the saturated and unsaturated fatty acids after this treatment (Ibrahim et al., 1987). In these works, gamma radiation led to an increase in the values of peroxide and saturated fatty acids in the milk, though a decrease of iodine and unsaturated fatty acids had taken place. In the work carried out by
Rady and Badr (2003), the irradiated product went to butter where an increase in the value of peroxide also took place, but the rate of iodine was not altered.

These results demonstrated that good correlation of the tests of TBA and NMR analyses. Thus, by the NMR the alteration of the milk fat using doses lower to $1 \mathrm{kGy}$ could not be considered as significant to the point of obstructing its application in this type of product.

\section{CONCLUSIONS}

From the results, it could be concluded that the formation of secondary products of lipid oxidation took place and that were detected by the methods of TBA and NMR; also, there was good correlation between these methods. The development of oxidative rancidness was small in the milk treated by the gamma radiation in the doses of 1 and $2 \mathrm{kGy}$.

\section{ACKNOWLEDGEMENTS}

The authors thank Doc. Edgar Francisco Oliveira de Jesus for irradiation process, Doc Eliane Teixeira Mársico and Eng. Carlos Frederico Guimarães for their technical assistance. The partial support of this work by Laboratory of the Co-ordinator of Graduate Programs in Engineering (COPPE) of the Federal University of Rio de Janeiro and Laboratory of Nuclear Magnetic Resonance of the Institute of Military Engineering (IME). Additional financial support was obtained from the University Federal Fluminense.

\section{REFERENCES}

Baky, A.A.A.; Farahat, S.M.; Rabie, A.M. and Mobasher, S.A. (1986), The manufacture of ras cheese from gamma irradiated milk. Food Chem., 20: 201-212.

Andreotti, G. E.; Trivellone, Lamanna, R.; Di Luccia, A.; Mott, A. (2000), Milk Identification of Different Species: ${ }^{13} \mathrm{C}-\mathrm{NMR}$ Spectroscopy Triacylglycerols from Cows and Buffaloes' Milks. $J$ Dairy Sci., 11, 83: 2432-2437.

Ciesla, K. ; Salmieri, S. ; Lacroix, M. and Tien, C. L.E. (2004), Gamma irradiation influence on physical properties of milk proteins. Rad. Physics Chem., 71 (1-2), 93-97.

\footnotetext{
${ }^{4} \mathrm{R}=$ Reproducibility, determined by the software SAS.
} 
Day, E.A.; Papaioannou, S.E. (1963), IrradiationInduced Changes in Milk Fat. $J$ Dairy Sci., 46,1201-1206.

Donnelly, J.K.; Robinson. D.S. (1995), Invited Review Free Radicals in Food. Free Radic. Research., 22 (2):147-176.

Dunkley, W.L; Jennings, W.G. (1951), A Procedure for Application of Thiobarbituric Acid Test to Milk. J. Dairy Sci., 34: 1064-1069.

Farkas, J. (2006), Irradiation for better foods. Trends Food Sci. Technol., 17:148-152.

Gava, A.J. (1999), Conservação dos Alimentos pelo Uso de Irradiação. In-Princípios de Tecnologia de Alimentos, ed. Gava, A.J. Nobel, São Paulo, pp. 271-277.

Guimarães, C. F.M; Silva, A. O. C.; Costa, F. M.; Jesus, E.F.O.; Mársico, E. T. (2005), Efeito da radiação gama sobre os componentes sólidos do lei cru. Paper presented at $2^{\text {th }}$ Congresso Latino Americano de Higienistas de Alimentos, $7^{\text {th }}$ Congresso Brasileiro de Higienistas de Alimentos, Búzios, Rio de Janeiro.

Gurgel, M.S.C.C.A. (2000), Efeito da radiação gama na resistência do Staphylococcus aureus (Rosembach, 1984) e nas propriedades físicoquímicas e sensoriais do queijo "Minas Frescal”. Doc. Thesis, Universidade de São Paulo, São Paulo, Brasil.

Hashisaka, A.E.; Matches, J.R.; Batters, Y.; Hungate, F.P.; Dong, F.M. (1990), Effects of Gamma Irradiation at $-78^{\circ} \mathrm{C}$ on microbial populations in dairy products. J Food Sci., 55, 1284-1289.

Hu, F; Furihata, K.; Ito-Ishida, M.; Kaminogawa, S.; Tanokura, M. (2004), Nondestructive observation of bovine milk by NMR Spectroscopy: Analysis of existing states of compounds and detection of new compounds. J. Agric. Food Chem., 52, 4969-4974.

Ibrahim, M.K.O; El-Batawy, M. A.; El-Sayed, S.A. (1987), Comparative studies on gamma irradiated fat dairy products. Egypt J Dairy Sci., 15 (2), 221228.
Kilcast, D. (1995), Food irradiation: Current problems and future potential. Int Biodeter. Biodegr., 36, 279-296.

King, R.L. (1962), Thiobarbituric acid reaction as a measure of oxidized flavor in milk and model systems. J Dairy Sci., 45 (10), 1165-1171.

Naghmoush, M. R.; Shehata, T.E.; Girgis, E.S.; Kamal, T.H.; Ibrahim, M.K. (1983), Egypt. J. Dairy Sci., 11 (1), 61-69.

Pietranera, M.S.A.; Narvaiz, P.; Horak, C.; Kairiyama, E. (2003), Irradiated Ice-creams for Immunosuppressed Patients. Radiat. Phys. Chem., 66, 357.

Rady, A. H.; Badr, H. M. (2003), Keeping the quality of cows' butter by $\gamma$-irradiation. Grasas y aceites, $\mathbf{5 4}$ (4), 410-418.

Rosenthal, I.; Martinot, M.; Lindner, P.; Juven, B.J.; Ben-Hur, E. (1983), A study of ionizing irradiation of dairy products. Milchwissenschaft, 38 (8), 467470.

SAS Institute. SAS User's Guide. 6.04 Edition. SAS Institute Inc., Cary, NC, 1999. 956p.

Schoonmaker, S. (2001), Irradiation destroys Johne's in milk. Dairy Herd Management. Set. 2001.

Searle, A. J. F.; McAthey, P. (1989), Treatment of Milk by Gamma Irradiation - Effect of Anoxia on Lipid Peroxidation and the Survival of Pseudomonas aeruginosas. J. Sci. Food Agric., 48 (3), 361-367.

Silva, A. C. O. (2003), Efeito da radiação gama e do conservante nisina sobre a enterotoxina $A$ produzida por Staphylococcus aureus adicionada ao leite usado na fabricação de queijo Minas frescal. Master Dissertation, Universidade Federal de Minas Gerais, Belo Horizonte, Brasil.

Received: September 22, 2010; Revised: January 21, 2011; Accepted: July 22, 2011. 